\title{
Quality of life in nursing home settings: Perspectives from elderly residents with frailty
}

\author{
Enid Wai-yung Kwong ${ }^{1}$, Claudia Kam-yuk Lai ${ }^{1}$, Faith Liu ${ }^{2}$ \\ 1. School of Nursing, The Hong Kong Polytechnic University, Hung Hom, Hong Kong, China. 2. Queen Elizabeth Hospital, \\ Hong Kong, China.
}

Correspondence: Enid Wai-yung Kwong. Address: School of Nursing, The Hong Kong Polytechnic University, Yuk Choi Road, Hung Hom, Hong Kong. Email: hsenid@inet.polyu.edu.hk

Received: November 11, 2013

Accepted: January 20, 2014

Online Published: January 23, 2014

DOI : $10.5430 /$ cns.v2n1p100

URL: http://dx.doi.org/10.5430/cns.v2n1p100

\begin{abstract}
Frailty in older people is a challenge for governments, policy makers and healthcare professionals. It decreases quality of life (QoL) in older people, particularly those in nursing home settings. By adopting exploratory qualitative design with focus group interviews, this study aimed to explore perception of QoL in Chinese nursing home residents with frailty to inform nursing care strategies for improving the QoL of Chinese nursing home residents with frailty. Twenty-four Chinese nursing home residents with the frailty scores of 2 or above and at least 18 in the Mini Mental State Examination formed four focus groups to share their views on QoL. Analyzed by qualitative content analysis, the focus group data identified five themes - physical well-being to maximize independence in self-care, peace of mind to cope with irreversible impairment, connection to society, fulfillment of basic needs, and harmony in interpersonal relationships - and four sub-themes.
\end{abstract}

\section{Key words}

Frailty, Quality of life, Nursing home residents

\section{I ntroduction}

In the face of an aging global population, frailty in older people is a challenge for governments, policy makers and healthcare professionals. Although there is no consensus definition for frailty ${ }^{[1]}$, it is commonly considered to be a state of high vulnerability that causes adverse health outcomes including disability, dependency, fall, the need for long-term care, and mortality ${ }^{[2]}$. Frailty is associated with dependence, long-term residential care, hospitalization and mortality in older people $^{[1,3]}$. There is general agreement as to the major impact of frailty on older people and their caregivers, the healthcare system and society ${ }^{[4]}$. Because enhanced longevity worldwide is allowing older people to live longer with chronic illnesses and long-term disabilities, it is anticipated that the prevalence of frailty in older people will continue to increase. In view of this fact, healthcare professionals and researchers in the field of geriatric care have put a priority on prevention and identification of frailty in older people, and care of frail older people.

Quality of life (QoL) is defined as "individuals" perception of their position in life in the context of the culture and value system in which they live and in relation to their goals, standards, and concerns” ${ }^{[5]}$. There is a general agreement that QoL is subjective, individualistic and multidimensional ${ }^{[6-8]}$. In addition, one’s feelings and judgment about his/her quality of 
life are embedded in his/her personal values, goals, histories, cultures, and life experiences ${ }^{[9]}$. In view of these QoL concepts, we believed that a subjective and qualitative approach to exploring the QoL of residents with frailty in nursing homes would provide more complex data than a quantitative approach in which QoL is measured by tools. However, most of the previous studies on QoL among older people in nursing homes adopted a quantitative design, and qualitative studies on QoL from the perspectives of residents with frailty in nursing homes are still lacking.

Nursing homes are the last resort for older people, so it is understandable that prevalence of frailty in such settings is more prevalent than in the community, and it is also anticipated that the prevalence is increasing. Lower QoL is perceived by those with frailty than by their less frail counterparts ${ }^{[10]}$. As a result, our care for residents with frailty in nursing homes should be focused on improving their QoL rather than simply increasing their longevity. Their self-reported QoL would give insights to enable nurses to plan appropriate strategies and/or interventions for improvement of their QoL.

In previous qualitative studies on QoL, there were three main groups of older people reporting their perceived QoL. They were community-dwelling older people, elderly residents in general and elderly residents with frailty from long-term care facilities. The samples of community-dwelling older people perceived that physical and functioning health, psychological well-being, social well-being (social network and relationships, help and support, engagement in social activities, accessible local facilities and services), pleasant home and neighbourhood, life satisfaction, philosophy of life, independence/control of life, economic well-being, feelings (respect, human dignity, love, caring, consideration), awareness and acceptance of unchangeable inevitable circumstances played a major role in their good quality of life ${ }^{[11-15]}$.

In three previous studies, elderly residents in general (without identification of frailty) from long-stay institutions in Ireland and south-west England had similar views on QoL to those of community-dwelling older people ${ }^{[16-18]}$. They perceived similarly that care environment and ethos care (promoting resident autonomy and choice, promoting and maintaining residents' independence, staff and the physical environment), activities and therapies (opportunities to pursue meaningful and purposeful activities), physical functioning (ability to perform activities of daily living and ability to engage in leisure activities for the sake of pleasure) were important for good quality of life. They also identified some unique concerns for quality of life while living in long-stay institutions, including connectedness (community, family, and religion), individuality (private space, personal possessions), personal identity (maintaining a sense of self and appearance) and professionalism (working attitude of nurses and individual care). Besides reporting QoL from the perspectives of residents in long-stay institutions, Conney and her team ${ }^{[16]}$ in the same study also found mediating, facilitating or constraining factors affecting QoL in residents in long-stay institutions. The mediating factors were adaptive response, life experiences, and health and dependency, while facilitating or constraining factors included physical and social environment.

Studies on the perceived QoL of frail elderly residents with impairments are few ${ }^{[19,20]}$. Tester's research team found that frail residents in care homes with severe physical and/or mental conditions or disabilities at the end of their lives considered four key inter-related areas for their QoL: sense of self (feeling of being at home, personal appearance and possessions, and preferences for personal space), the care environment (promoting resident autonomy, choices, right to control their lives, and assertiveness), relationships (personal relationships, communication and interaction with residents, relationship with family) and activities (engaging in meaningful activities) ${ }^{[19]}$. Among these key areas, sense of self, care environment and activities were similarly reported by elderly residents in general from long-stay institutions as being important for their QOL ${ }^{[16-18]}$. In another study by Hjaltadóttir and Gústafsdóttir ${ }^{[20]}$, nursing home residents who were physically frail but lucid expressed that bodily insecurity (being safe, being cared for, and maintaining the body), seeking solace (the disparate community, keeping oneself in seclusion, feeling at home and having a habitual way of being, and overstepping the confinement), and preparing for departure and affirmation of self (being recognized as a person, family relations, the lived past, and doing meaningful things) were the important domains of their QoL. The previous studies have revealed that older people with different health status from various living environments have specific issues that are of particular concern and that they perceive to be important. 
QoL perception and living experience of older people are influenced by ethnicity ${ }^{[19]}$. There was only one Taiwan study to explore Chinese older people's perception of QoL ${ }^{[21]}$. It identified six dimensions of QoL for Chinese older people from residential care homes and in the community: physical health (physical well-being, impact of illness, medical care), psychological health (mood states, life attitude and retrospection, philosophy of living, self-efficacy), social function (connectedness, exercise and leisure activities, social activities and services), the living environment (living environment and arrangements, institutional factors), economic status, and religion and death. These study findings were not only applicable to residents from long-term care settings but also from the community. There were no previous studies reporting Chinese older people with frailty in nursing homes which is a type of long-term residential care homes. Therefore, the current study aiming to explore QoL from the perspectives of Chinese nursing home residents in Hong Kong to address this gap.

\section{Methods}

\subsection{Design and participants}

This study adopted a descriptive qualitative design with focus group interviews. It involved a convenience sample of 24 elderly residents from two nursing homes in Hong Kong, operated by a Hong Kong non-governmental organization which is managed by the Welfare Social Department (SWD) of Hong Kong. Residents in Hong Kong nursing homes managed by the SWD tend to have poor health or physical and/or mild mental disabilities ${ }^{[22]}$, but they are not generally as frail as those in the nursing homes managed by the Hong Kong Department of Health. The study criteria were living in one of the two nursing homes for at least three months before the time of collecting the data, having achieved a score of 2 or above in Rockwood et al.'s frailty scale ${ }^{[23]}$, and a score of at least 18 in the Mini Mental State Examination (MMSE) ${ }^{[24]}$, which meant that they were able to respond reliably in in-depth interviews on their quality of life ${ }^{[25]}$.

\subsection{Measures}

\subsubsection{Chinese version of Mini Mental State Examination (C-MMSE)}

The MMSE was originally designed for use in assessing cognitive function in clinical settings and in research ${ }^{[24]}$. We adopted the Chinese version of the MMSE to identify eligible participants and identify the cognitive function of the participants for this study. It measures seven dimensions of cognition and has demonstrated good reliability and validity ${ }^{[26,27]}$. The scores range from 0 to 30 , with higher scores indicating better cognitive function. It has good internal consistency, with a Cronbach's alpha of 0.86, a good test-retest reliability coefficient of 0.78 , and excellent inter-rater reliability (ICC=0.99). A cut-off score of 20 demonstrated the best balance between sensitivity of $97.5 \%$ and specificity of $97.3 \%$ in samples consisting of older people ${ }^{[28]}$.

\subsubsection{Frailty scale}

Rockwood et al.'s frailty scale ${ }^{[23]}$ was employed to identify eligible participants for this study. It covers four domains (mobility, activities of daily living, continence, and cognition), and identifies four levels of progressive impairment, from level 0 to level 3. Level 0 indicates a non-frail participant, while level 1 indicates those with bladder incontinence only. Level 2 indicates those who need assistance in mobility or in at least one (two if incontinent) basic activities of daily living (ADL), or who have cognitive impairment without dementia. Level 3 identifies those who are totally dependent on others for transfers, or who need assistance in at least two (three if incontinent) basic ADLs, or who have double incontinence and a diagnosis of dementia ${ }^{[23]}$. This scale is short, simple, and user-friendly, and its domains are common health issues faced by older people, particularly those living in long-term residential care facilities, so it is suitable for use in this study to identify nursing home residents with frailty. The Chinese version of MMSE and the Chinese version of the modified Barthel Index were used to confirm the frailty level (level 2 or level 3) of the participants. 


\subsubsection{Resident record}

Each resident has his/her own resident record, which is kept in the nursing home in which that resident lives. Each resident record is reviewed periodically to ensure that the data in the record is kept up-to-date. For this study, data consisted of those on demographics (age, gender, marital status, length of stay in nursing home) and performance in activities of daily living (ADL). For the participants' performance in ADL, the Chinese version of the Barthel Index was adopted as an assessment tool. The Barthel Index ${ }^{[29]}$ was first published in 1965 and includes ten items: personal hygiene, bathing, feeding, toileting, stair climbing, dressing, bowel control, bladder control, ambulation or wheelchair and chair-bed transfer. The scores for each item range from 0 to 5,10 , or 15 , with 0 indicating total dependence and 5 , 10 , or 15 indicating total independence. Its total score is 100 , higher scores indicating better performance in self-care. The Barthel Index was modified in 1979 to include $0-10$ points for each item ${ }^{[30]}$, and was further standardized the rating criteria and revised the scale into a five-point Likert format to improve its discriminative power ${ }^{[31]}$. The Chinese version of the modified Barthel Index also consists of ten items with a total score of 100, ranging from 0-10 for each item. The higher the total score, the better the performance in self-care. The kappa values for inter-rater reliability for all items ranged from 0.81 to 1.00 , and the Cronbach's alpha for internal consistency was $0.93^{[32]}$.

\subsection{Data collection methods}

The interview guide designed by our research team based on the QoL literature reviewed was used to facilitate the participants' discussion of their QoL perception in the focus group interviews. It consists of four major questions: (1) How do you feel about living in the nursing home? (2) What is most important and concerns you most about your current situation for a good life? (3) What are your wishes in the current situation for a good life? (4) What are the conditions, aspects and/or issues that might help you have a good life or threaten your good life at present? The guide was validated by an experienced nurse working in a nursing home and a gerontology nursing researcher. It was also piloted with two nursing home residents in an interview, and a minor change of several words was made to the guide afterward to ensure that the questions were easily understood. Our research team previously conducted a survey to examine the QoL of 91 residents from two nursing homes. From the sample of this previous survey, a total of 24 participants (12 from each nursing home) were recruited. They met the selection criteria of this current study, were observed to be more active and vocal in responding to the questions during the data collection for the survey, and were also willing to share their views on QoL with other residents in the focus groups.

There were two focus groups in each home, with six participants in each group: four with a frailty level of 2 and two with a frailty level of 3 . Before the focus group interviews, a pilot study was conducted and the interview was evaluated. No major changes were needed after the pilot study. In the main study, the trained RA independently led the discussion in each group to enable the participants to freely express their concerns, important issues and wishes with respect to their present situation for a good life. The RA intentionally used the term "good life" instead of "quality of life" in the interview, because "good life" is more understandable to the participants. Each group interview took around 60-70 minutes. With the agreement of the participants, all interviews were audio-taped for verbatim transcription to aid data analysis.

\subsection{Data analysis}

The quantitative data were analyzed using IBM SPSS statistical software (version 19$)^{[33]}$. The participants' demographics and performance in ADL were analyzed using descriptive statistics that included percentages, frequencies, and mean values. The data from the focus group interviews were subjected to qualitative content analysis. The software, e.g NVivo was not used for the data analysis in this study because the data were not much which were from four focus groups. The RA transcribed the data. Two authors of this study and the RA of this study reviewed the transcripts independently and then discussed the discrepancies that they had identified in order to achieve a comprehensive view of the data in its totality and to come to a consensus. The first author of and the RA further analyzed the data independently by coding and creating sub-themes to derive themes ${ }^{[34]}$. Two authors including the first author and the RA then met to clarify and discuss the discrepancies of the sub-themes and themes identified and came up with the conclusion for revision of the sub-themes and 
themes. After completion of the revision, two more meetings were conducted among three of us again for discussion and consensus of the sub-themes and themes.

\subsection{Ethical considerations}

Before the commencement of the study, ethical approval was obtained from the Human Ethics Committee of the first author's university. Access approval was obtained from the two nursing homes. Before starting the focus group interviews, the RA obtained informed written consent from participants with MMSE scores of 20 or above, and from the family members of those with MMSE scores of 19 or below. The participants were assured that there would be no penalties if they refused to answer any questions or if they withdrew from our study, which they were free to do at any time. They were also given strong assurances of anonymity and confidentiality.

\section{Results}

\subsection{Participant profile}

A total of 24 residents with a frailty level of $2(n=16,66.7 \%)$ or $3(n=8,33.3 \%)$ participated in the focus group interviews. They ranged in age from 65 to 78 with a mean age of 79.86. Fifteen of them (62.5\%) were female, while sixteen (66.7\%) had no spouse. The mean ADL was 45.82 with a range of 40-80, and ten (41.7) of them were cognitively normal (see Table 1).

Table 1. Participants' profile ( $\mathrm{N}=24)$

\begin{tabular}{llll}
\hline Characteristics & Mean(SD) & Range & n (\%) \\
\hline $\begin{array}{l}\text { Age } \\
\text { Gender }\end{array} \quad$ (65-78) & \\
$\quad$ Male & & $9(37.5)$ \\
$\quad$ Female & & $15(62.5)$ \\
Marital status & & \\
$\quad$ With spouse & & 8 (33.3) \\
$\quad$ Without spouse & & $16(66.7)$ \\
Frailty level & & \\
$\quad$ Two & & $16(66.7)$ \\
$\quad$ Three & & & $8(33.3)$ \\
Length of stay (in months) & $15.79(4.17)$ & $(10-21)$ & $10(41.7)$ \\
Cognitive function & $19.17(1.34)$ & $(18-22)$ & $14(58.3)$ \\
Normal & & & \\
Impaired (MMSE <20) & & & \\
\hline
\end{tabular}

\subsection{Perception of QoL}

Five themes were identified in relation to the participants' perceived major concerns, wishes and what they viewed as important in their current nursing home lives. The themes were physical well-being to maximize independence in self-care, peace of mind to cope with irreversible impairment, fulfillment of basic needs, connection to society (enjoyment in participating in outdoor activities, the feeling of being cared for and supported by family members and volunteers), and 
harmony in interpersonal relationships. The data by the frailty level at 2 and 3 were also analyzed but the thematic differences were minimal. The themes, sub-themes and representative verbatim are noted in Table 2.

Table 2. Quality of life

\begin{tabular}{|c|c|c|c|}
\hline & Themes & Sub-themes & Representative verbatim statements \\
\hline \multirow[t]{2}{*}{1} & $\begin{array}{l}\text { Physical well-being to } \\
\text { maximize independence } \\
\text { in self-care }\end{array}$ & $\begin{array}{l}\text { Pain leading to poor sleep } \\
\text { quality and impaired } \\
\text { mobility }\end{array}$ & $\begin{array}{l}\text { I had severe pain in my leg at night, which caused me to be unable to } \\
\text { sleep well.... The most important thing is not to have too much } \\
\text { suffering and pain. Otherwise, we could not sleep and walk, and would } \\
\text { have to rely on other people's assistance and care. This would be so } \\
\text { sad. }\end{array}$ \\
\hline & & $\begin{array}{l}\text { Impaired mobility causing } \\
\text { limited self-control over } \\
\text { their lives }\end{array}$ & $\begin{array}{l}\text { I need to sleep on the bed most of the time, which is very hard and } \\
\text { extremely annoying. The time passes very slowly.... When I sleep on } \\
\text { the bed at night, I hope daytime will come quickly because sleeping } \\
\text { for a very long time is very bad. In the daytime, I hope the evening will } \\
\text { come fast, because sitting too long is also very hard, but I am unable to } \\
\text { go back to bed. I wish I could walk and did not need to rely on other } \\
\text { people's care. }\end{array}$ \\
\hline 2 & $\begin{array}{l}\text { Peace of mind to cope } \\
\text { with irreversible } \\
\text { impairment }\end{array}$ & & $\begin{array}{l}\text { I am empty and bored ... unable to walk and go out on my own. I just } \\
\text { want to be in a peaceful state of mind and to stay pleasant. }\end{array}$ \\
\hline \multirow[t]{2}{*}{3} & Connection to society & $\begin{array}{l}\text { Engaging in participation } \\
\text { in outdoor activities }\end{array}$ & $\begin{array}{l}\text { I have not gone out for years, except when taken for a medical } \\
\text { follow-up. I wish I did not have to stay in the nursing home all the } \\
\text { time, but I am not able to leave it independently.... I feel good even } \\
\text { when they just bring me out to wander for a short period of time. }\end{array}$ \\
\hline & & $\begin{array}{l}\text { Being cared for and } \\
\text { supported by family } \\
\text { members and volunteers }\end{array}$ & $\begin{array}{l}\text { My adult children visit me every Sunday, so I do not feel unhappy in } \\
\text { the nursing home. } \\
\text { A volunteer from a university visits me every Saturday. We chat } \\
\text { happily and openly.... We enjoy talking with each other. I feel less } \\
\text { bored and my negative mood is relieved.... }\end{array}$ \\
\hline 4 & $\begin{array}{l}\text { Fulfillment of basic } \\
\text { needs }\end{array}$ & & $\begin{array}{l}\text { I am happy and satisfied with the life here because I have sufficient } \\
\text { food to eat, three meals a day and sufficient clothing to keep warm. I } \\
\text { could not wish for more at this time. }\end{array}$ \\
\hline 5 & $\begin{array}{l}\text { Harmony in } \\
\text { interpersonal } \\
\text { relationships }\end{array}$ & & $\begin{array}{l}\text { We live here together..., hoping to have a happy life in this living } \\
\text { environment. Thus it is necessary to be friendly and kind to each } \\
\text { other... We need to accept each other's weaknesses and not be } \\
\text { hostile. }\end{array}$ \\
\hline
\end{tabular}

\subsubsection{Physical well-being to maximize independence in self-care}

There are two sub-themes: pain leading to poor sleep quality and impaired mobility and impaired mobility limited self-control over their lives. Because of suffering from severe pain, some participants were unable to sleep well and had impaired mobility that must require assistance in their daily care. In addition, due to their impaired mobility, some participants relied on staff cargivers' assistance in transfer so they stayed in their beds or sit on the chairs for a long time. They thought dependence in ADL at the current situation was poor quality of life and hoped to maximize their self-care ability.

\subsubsection{Peace of mind to cope with irreversible impairment}

Due to physical impairment, majority of participants were unable to go out without assistance. They felt upset, empty and bored. Knowing that this situation was unchanged and the impairment was irreversible so they tried their best to keep themselves peaceful in mind and stay pleasant for better quality of life. 


\subsubsection{Connection to society}

There are two sub-themes including engaging in participation in outdoor activities and being cared for and supported by family members and volunteers. Since some participants were unable to leave the nursing homes without assistance, they wished to be brought out to wander for a while which would be good for them, because they stayed in the nursing homes all the time. Some participants were regularly visited by their family members or volunteers so they were happy and have less negative mood.

\subsubsection{Fulfillment of basic needs}

Some participants expressed that they were satisfied with the lives in the nursing homes. It is because they were provided with care, sufficient food and clothes. They required no more at the current situation.

\subsubsection{Harmony in interpersonal relationships}

Some participants hoped to have a happy life in the nursing homes so they expected that the nursing home residents were friendly and kind to each others and also accepted each others' weakness. This would help to built up harmonious interpersonal relationships among the residents in the nursing homes that could improve quality of life among the residents.

\section{Discussion}

Overall, the study sample had moderate deficiency in ADL and/or cognitive impairment. Their length of stay in the nursing homes was short, with an average of 16 months, because home A had been re-organized as a nursing home setting for only around 2.5 years and home B was a new nursing home that had been established for just about 1.5 years at the time of the data collection.

Physical well-being was a theme identified in this study. The participants were most concerned about their physical well-being to maximize their independence in the area of self-care in order to live a good life in the nursing home. Because of pain and suffering, they could not sleep well and had difficulty in walking, resulting in a need for greater assistance in their activities of daily living. They had limited control of their own daily activities, such as they when they got out of bed in the morning and went back to bed to rest, resulting in their sitting in a chair for long periods of time. All of these factors caused them physical and psychological distress. This theme is similar to those found in previous studies reporting that physical and functional health, independence, having good health and mobility, and retaining one's independence and

control over life were the QoL themes for community-dwelling older people ${ }^{[11,12-15]}$, in addition to physical functioning to perform activities of daily living for residents in long-stay institutions ${ }^{[16]}$. Several quantitative studies also supported this theme that pain ${ }^{[35-37]}$ and performance in activities of daily living ${ }^{[38,39]}$ were associated with the QoL of nursing home residents.

Another theme, "peace of mind to cope with irreversible impairment", is a new theme identified specifically for nursing home residents with physical and/or mental frailty in this study. The participants suffered from psychological distress caused by irreversible impairments, such as impaired mobility. They seemed to accept that this situation would not change, and came to wish for psychological comfort in the form of a quiet and pleasant state of mind to achieve good QoL. Two previous studies also reported similar QoL themes: psychological well-being for older people in the community ${ }^{[11]}$ and having a positive frame of mind for Chinese residents in residential care homes and community-dwelling older people ${ }^{\text {[21] }}$.

In this study, the participants connected to society through outdoor activities and support from family and volunteers for their good quality of life. They enjoyed outdoor activities but had no or very few opportunities to join these activities and thus wished to have the opportunity to go out in order to cheer up. The poor health status of frail nursing home residents, inadequate manpower in nursing homes and nursing home staffs' negative attitude towards frail residents' participation in social activities might be possible reasons for having fewer opportunities to join in outdoor activities. The importance of 
engaging in social activities and social function for good quality of life was also reported in the previous studies with community-dwelling older people ${ }^{[12-15]}$, residents in general from long-stay institutions ${ }^{[17,18,21]}$, and nursing home residents with frailty ${ }^{[19]}$. In addition, through regular visits from family members and volunteers, the participants gained social support and had the feeling of being cared for, which contributed to their positive frame of mind. All of these factors provided frail nursing home residents with deficiency in ADL with opportunities to continue connecting with society in order to maintain enjoyment in their lives and improve their outlook. Volunteer support is crucial, especially for frail nursing home residents without family support and with ADL dependence. Visits from volunteers provided opportunities for nursing home residents to freely express their feelings and views about their personal affairs and institutional life without fear of consequences, which likely helped to enhance their overall well-being. This sub-theme, feeling being cared for and supported by family and volunteers, is similar to the QOL themes of connectedness to community and family, identified in residents in long-stay institutions in previous studies ${ }^{[16,17]}$, and of relationship with family, identified in nursing home residents with frailty ${ }^{[19]}$. It also supports the findings of two previous quantitative studies reporting that monthly family contact and participation in social activities is associated with QoL among frail residents with functional impairments in residential care facilities, 40 and that regular visits from volunteers increased the well-being of nursing home residents with dementia ${ }^{[41]}$. "Volunteer support" is a newly identified theme in this study for nursing home residents with physical and/or mental frailty.

"Fulfillment of basic needs" and "harmony in interpersonal relationships" are new findings in this study. No similar findings have been reported previously in either quantitative or qualitative studies. The participants were satisfied with their lives in the current living environment, where they were provided with sufficient food and clothes. Fulfillment of basic needs was an important aspect in their life satisfaction for achieving a good quality of life. Like many elderly Chinese in Hong Kong, the participants might have come from mainland China. They might have experienced hardship in their lives, especially during the time of the Sino-Japanese War and the Civil War between the years of 1937 and 1950 in mainland China. As a result, their current living environment, with sufficient food and clothes, might be perfectly satisfactory to them.

Harmony in interpersonal relationships, which is embedded in traditional Chinese culture, is derived from the famous Chinese philosopher, Confucius. The thoughts of Confucius are a system of philosophy that is well known as Confucianism. In summary, the Confucian belief is that the shortest path to benevolence is by trying our best to treat others as we ourselves would wish to be treated. This is the core concept in the Confucian idea of the harmony required to achieve a harmonious society ${ }^{[42]}$. This is similar to the participants' belief and hope that being kind, friendly, and understanding to each other, and accepting each other, which is the way people like to be treated, would allow harmonious relationships to develop in the nursing homes. The nursing home setting is indeed a small society in which residents with various personalities, characters, values, backgrounds, and living habits can easily come into conflict with one another, particularly those who are frail and who are thus confined to the nursing home. In addition, many Hong Kong nursing homes that are subsidized by the government commonly allocate four to six residents to a room, which is also a source of conflict. The residents thus wish to have harmonious interpersonal relationships with their peers in order to lead a peaceful and happy life in the nursing home, consistent with Mitchell and Kemp's finding ${ }^{[40]}$ that a low level of conflict in an environment improved the QoL of functionally impaired residents.

Several themes in this study were inter-related: physical well-being to maximize dependence in self-care, peace of mind to cope with irreversible impairment, connection to society via engaging in outdoor activities, and harmony in interpersonal relationships. If nursing home residents have good physical well-being, they need less assistance and care from others, resulting in more opportunities for joining social activities. In addition, harmony in interpersonal relationships with other residents allows residents to receive more support from each other while living in the nursing home. All these factors contribute to their good psychosocial health, which will help them to cope with their frailty. 


\section{I mplications for clinical nursing practice}

These five themes can be organized as a model of QoL for nurses working with other health disciplines to plan care strategies to enhance the QoL of nursing home residents with physical and/or mental frailty. Strategies can be considered to enhance the communication of pain between frail residents and staff for early diagnosis and timely and adequate treatment of pain. Apart from adequate and dignified assistance in activities of daily living for residents with frailty, it is necessary to develop a physical exercise program to prevent muscle atrophy and improve their muscle tone and strength. Social activities organized for frail residents should be provided regularly, and nursing strategies for working closely with families and also for recruiting and mobilizing volunteers should be considered for more family and volunteer support to enhance the psychosocial well-being of residents with frailty. In addition, developing a culture of understanding and acceptance among nursing home residents is a strategy to help them to build up harmonious interpersonal relationships with others in order to achieve a good quality of life.

\section{Conclusion}

This is the first study to explore QoL from the perspectives of Chinese nursing home residents with physical and/or mental frailty. It has affirmed the importance of physical well-being to maximize independence in self-care, and connection to society through engaging in outdoor activities and family in achieving good quality of life in older people living in the community and long-term care facilities, no matter whether or not they are frail. "Having a peaceful mind to cope with irreversible impairment" and "connection to society through volunteer visits" are the specific QoL themes identified for frail nursing home residents with physical and/or mental impairments, while "fulfillment of basic needs" and "harmony in interpersonal relationships" are newly-identified themes/ sub-themes especially for Chinese nursing home residents with frailty in this study. This study has added new knowledge for areas regarding QoL and frailty. It has provided valid data to inform the development of care strategies to improve the QoL of Chinese nursing home residents with physical and/or mental frailty. Further studies with samples from other types of long-term residential care homes are highly recommended in order to confirm the findings, especially those newly identified for developing a comprehensive QoL model for older people with frailty in long-term residential care settings.

\section{References}

[1] Fried LP, Tangen CM, Walston J, et al. Frailty in older adults: evidence for a phenotype. J Gerontol Med Sci. 2001; 56A: M146-M156. http://dx.doi.org/10.1093/gerona/56.3.M146

[2] Fried LP, Ferrucci L, Darer J, Williamson JD \& Anderson G. Untangling the concepts of disability, frailty and comorbidity: Implications for improved targeting and care. Journal of Gerontol Med Sci. 2004; 59(3): 255-263. http://dx.doi.org/10.1093/gerona/59.3.M255

[3] Fried LP, Ferrucci L, Darer J, et al. Untangling the concepts of disability, frailty, and comorbidity: implications for improved targeting and care. J Gerontol A Biol Sci Med Sci. 2004; 59: 255-63. http://dx.doi.org/10.1093/gerona/59.3.M255

[4] Bergman H, Ferrucci L, Guralnik J, et al. Frailty: an emerging research and clinical paradigm issues and controversies. J Gerontol A Biol Sci Med Sci. 2007; 62:731-737. http://dx.doi.org/10.1093/gerona/62.7.731

[5] WHO QOL Group. World Health Organization Quality of Life-100. World Health Organization Division of Mental Health, Geneva. 1995. http://dx.doi.org/10.1093/ageing/21.2.142

[6] Fletcher AE, Dickinson EJ, Philp I. Review: Audit Measures: Quality of life instruments for everyday use with elderly patients. Age Aging. 1992; 21(2): 142-150.

[7] Lawton MP. Measures of quality of life and subjective well-being. Generations. 1997; 21(1): 45-47.

[8] Ferrell BR, Grant M, Fund B, et al. Quality of life in breast cancer part II: psychological and spiritual well being. Cancer Nurs. 1998; 21: 1-9. http://dx.doi.org/10.1097/00002820-199802000-00001

[9] Faden R, German PS. Quality of life: considerations in geriatrics. Clin in Geriatr Med. 1994; 10: 541-551.

[10] Puts MT, Shekar y N, Widdershoven G, et al. What does quality of life mean to older frail and non-frail community-dwelling adults in the Nether lands? Qual Life Res. 2007; 16(2): 263-277. http://dx.doi.org/10.1007/s11136-006-9121-0 
[11] Lau A, Chi I, McKenna K. Self-perceived quality of life of Chinese elderly people in Hong Kong. Occup Ther Int. 1998; 5(2): 118-139. http://dx.doi.org/10.1002/oti.71

[12] Berglund AL, Ericsson K. Different meanings of quality of life: a comparison between what elderly persons and geriatric staff believe is of importance. Int J Nurs Practice. 2003; 9: 112-119. http://dx.doi.org/10.1046/j.1322-7114.2003.00414.x

[13] Bowling A, Gabriel Z, Dykes J, et al. Let's ask them: A national survey of definitions of quality of life and enhancement among people aged 65 and over. Int J Aging Hum Dev. 2003; 56(4): 269-306. http://dx.doi.org/10.2190/BF8G-5J8L-YTRF-6404

[14] Gabriel Z, Bowling A. Quality of life from the perspectives of older people. Ageing Soc. 2004; 24: 675-691. http://dx.doi.org/10.1017/S0144686X03001582

[15] Borglin G, Edberg A, Rahm Hallberg I. The experience of quality of life among older people. J Aging Stud. 2005; 19(2): $201-220$. http://dx.doi.org/10.1016/j.jaging.2004.04.001

[16] Oleson M, Heading C, Shadick KM, et al. Quality of life in long-stay institutions in England: nurse and resident perceptions. J Adv Nurs.1994; 20: 23-32. http://dx.doi.org/10.1046/j.1365-2648.1994.20010023.x

[17] Murphy K, Shea EO, Cooney A. Quality of life for older people living in long-stay settings in Ireland. J Clin Nurs. 2007; 116: 2167-2177.

[18] Cooney A, Murphy K, O’shea E. Resident perspectives of the determinants of quality of life in residential care in Ireland. J Adv Nurs. 2009; 65(5): 1029-1038. http://dx.doi.org/10.1111/j.1365-2648.2008.04960.x

[19] Tester S, Hubbard G, Downs M, et al. Frailty and institutional life. In: Walker A, Hennessy CH. (ed.). Growing Older Quality of Life in Old Age. Maidenhead: Open University Press. 2004; 189-209.

[20] Hjaltadóttir I, Gústafsdóttir M. Quality of life in nursing homes: perception of physically frail elderly residents. Scand J Caring Sci. 2007; 21(1): 48-55. http://dx.doi.org/10.1111/j.1471-6712.2007.00434.x

[21] Leung KK, Wu EC, Lue BH, et al. The use of focus groups in evaluating quality of life components among elderly Chinese people. Qual Life Res. 2004; 13: 179-190. http://dx.doi.org/10.1023/B:QURE.0000015291.79826.a8

[22] Social Welfare Department. Services for the Elderly[Internet]. 2012[cited 2012 Dec. 12]. Available from: http://www.swd.gov.hk/en/index/site_pubsvc/page_elderly/

[23] Rockwood K, Stadnyk K, MacKnight C, et al. A brief clinical instrument to classify frailty in elderly people. Lancet. 1999; 353(9148): 205-206. http://dx.doi.org/10.1016/S0140-6736(98)04402-X

[24] Folstein MF, Folstein SE, McHugh PR. "Mini-mental state". A practical method for grading the cognitive state of patients for the clinician. J Psychiatr Res. 1975; 12 (3): 189-198. http://dx.doi.org/10.1016/0022-3956(75)90026-6

[25] Mozley CG, Huxley P, Sutcliffe C, et al. 'Not knowing where I am does not mean I do not know what I like’: Cognitive impairment and quality of life response in elderly people. Int J Geriatr Psychiatry. 1999; 14(9): 776-783.

http://dx.doi.org/10.1002/(SICI)1099-1166(199909)14:9<776::AID-GPS13>3.0.CO;2-C

[26] Anthony JC, LeResche L, Niaz U, et al. Limits of the 'Mini-Mental State' as a screening test for dementia and delirium among hospital patients. Psycho Med. 1982; 12(2): 397-408. http://dx.doi.org/10.1017/S0033291700046730

[27] O'Connor DW, Pollitt PA, Hyde JB, et al. The reliability and validity of the Mini-Mental State in a British community survey. J Psychiatr Res. 1989; 23(1): 87-96. http://dx.doi.org/10.1016/0022-3956(89)90021-6

[28] Chiu HFK, Lee HC, Chung WS, et al. Reliability and validity of the Cantonese version of the Mini-Mental State Examination Preliminary study. J Hong Kong Coll Psychiatry. 1994; 4: 25-28.

[29] Mahoney FI, Barthel DW. Functional evaluation: the Barthel Index. Maryland State Med J. 1965; 14: 61-65.

[30] Granger CV, Dewis LS, Peters NC, et al. Stroke rehabilitation: analysis of repeated Barthel index measures. Arch. Phys. Med. 1979; 60(1): 14-7.

[31] Shah S, Vanclay F, Cooper B. Improving the sensitivity of the Barthel Index for stroke rehabilitation. J Clin Epidemiol. 1989; 42(8): 703-9. http://dx.doi.org/10.1016/0895-4356(89)90065-6

[32] Leung SO, Chan CC, Shah S. Development of a Chinese version of the Modified Barthel Index - validity and reliability. Clinl Rehabil. 2007; 21(10): 912-922. http://dx.doi.org/10.1177/0269215507077286

[33] Darren G, Mallery P. IBM SPSS statistics 19: step by step : a simple guide and reference (12th ed). Boston, Mass: Pearson. 2012.

[34] Elo S, Kyngäs H. The qualitative content analysis process. J Adv Nurs. 2008; 62(1): 107-115. http://dx.doi.org/10.1111/j.1365-2648.2007.04569.x

[35] Ballard C, O’Brien J, James I, et al. Quality of life for people with dementia living in residential and nursing home care: the impact of performance on activities of daily living, behavioral and psychological symptoms, language skills, and psychotropic drugs. Int Psychogeriatr. 2001; 13(1): 93-106. http://dx.doi.org/10.1017/S1041610201007499

[36] Luleci E, Hey W, Subasi F. Assessing selected quality of life factors of nursing home residents in Turkey. Arch Gerontol Geriatr. 2007; 46(1): 57-66. http://dx.doi.org/10.1016/j.archger.2007.02.007 
[37] Degenholtz H, Rosen J, Castle N, et al. The association between changes in health status and nursing home resident quality of life. Gerontologist. 2008; 48(5): 584-592. http://dx.doi.org/10.1093/geront/48.5.584

[38] Kato C, Ida K, Kawamura M, et al. Relation of falls efficacy scale (FES) to quality of life among nursing home female residents with comparatively intact cognitive function in Japan. Nagoya J Med Sci. 2008; 70(1-2): 19-27.

[39] Zanocchi M, Maero B, Nicola E. Chronic pain in a sample of nursing home residents: prevalence, characteristics, influence on quality of life (QoL). Arch Gerontol Geriatr. 2008; 47(1): 121-128. http://dx.doi.org/10.1016/j.archger.2007.07.003

[40] Mitchell J, Kemp BJ. Quality of life in assisted living homes: A multidimensional analysis. J Gerontology B Psychol Sci Soc Sci. 2000; 55(2): 117-127. http://dx.doi.org/10.1093/geronb/55.2.P117

[41] Oppikofer S, Albrecht K, Schelling HR et al. Effects of social support on well-being of demented nursing home residents. The Käferberg Visitation Study. Zeitschrift für Gerontologie und Geriatric. 2002; 35(1): 39-48. http://dx.doi.org/10.1007/s003910200005

[42] Mencius: The Warring States Period. (about 372-289 BC). Mencius, Human Nature; pp. 380-389. In: Gupta B, \& Mohanty J. (ed). Philosophical Questions: East and West (Philosophy and the Global Context). Rowman \& Littlefield Publishers, Inc., 2000. 